\title{
Evolução e qualificação do emprego formal no sul do Brasil
}

\begin{abstract}
Resumo
Este artigo analisa a evolução e a qualificação do emprego formal na Região Sul do Brasil, no período de 2005 a 2014. Trata-se de um estudo descritivo, com abordagem qualitativa, de dados da Relação Anual de Informações. Os resultados demonstraram que as microrregiões do Sul do Brasil obtiveram evolução crescente dos postos formais de trabalho nesse período. As atividades de Serviços, Indústria de Transformação e Comércio obtiveram as maiores taxas de participação relativa no total de empregos formais; e a Construção Civil teve a maior taxa de crescimento médio anual. Houve crescimento da participação relativa da mulher no mercado de trabalho e se observou um aumento no nível de escolaridade dos trabalhadores. $\mathrm{O}$ número de empregos formais que recebem até cinco salários mínimos aumentou enquanto o daqueles que recebem de cinco até mais de vinte salários mínimos diminuiu.
\end{abstract}

Palavras-chave: Economia brasileira; Economia regional; Economia do trabalho; Emprego formal

\section{Classificação JEL: J21, R11, R23}

\begin{abstract}
:
This article analyzes the development and qualification of formal employment in Southern Brazil, from 2005 to 2014. This is was a descriptive study with a qualitative approach, data from the Relação Anual de Informações. The results showed that the micro-regions of southern Brazil achieved growing evolution of formal jobs in the period. The service activities, Manufacturing Industry and Trade obtained the highest rates of relative share of total formal employment. The Construction had the highest rate of annual growth. There was growth in the share of women in the labor market. There was an increase in the educational level of workers. The number of formal jobs earning up to five minimum wages increased while receiving five to more than twenty minimum wages declined.
\end{abstract}

Palavras-chave: Brazilian economics; Regional economics; Labor economics; Formal employment 


\section{INTRODUÇÃO}

Este estudo analisa a evolução e a qualificação do emprego formal no Sul do Brasil e em suas respectivas microrregiões. A realização da análise utiliza-se da estatística descritiva, a partir de dados da Relação Anual de Informações Sociais (RAIS), referentes ao período de 2005 a 2014. A ideia norteadora deste estudo foi a pesquisa de Mattei e Venturi (2007), em que discutem a evolução e a qualificação do mercado formal de trabalho no Estado de Santa Catarina, no período de 1991 a 2005. No entanto, este estudo amplia a pesquisa para os outros estados do Sul do Brasil (Paraná e Rio Grande do Sul), em uma análise que enfoca as microrregiões desses estados.

O mercado formal de trabalho é aquele em que o empregado possui carteira de trabalho assinada, com contrato formalizado, o que garante ao colaborador o acesso ao sistema de seguridade social e aos diversos direitos trabalhistas (BALTAR et al., 2010). Dessa forma, a evolução do estoque de emprego formal de um determinado país, estado, região ou município significa que um maior número de trabalhadores possui proteção em situações de doença, acidente e desemprego, bem como preserva diversos direitos, dentre eles: salário mínimo, décimo terceiro salário, férias, licença maternidade e paternidade.

Nesse sentido, cabe mencionar que o Brasil tem presenciado, principalmente a partir de 2004, consideráveis taxas de crescimento do mercado formal de trabalho. O aumento dessas taxas de empregos formais tem-se dado principalmente pelo crescimento da economia brasileira no decorrer da década de 2000, o que proporcionou diversas alterações no mercado de trabalho do país: redução das taxas médias de desemprego, elevação do emprego assalariado formal, aumento do emprego em setores mais organizados da economia (incluindo a grande empresa e o setor público), crescimento do valor real do salário mínimo e redução do trabalho não remunerado. Além da questão econômica, outros fatores também motivaram o aumento crescente do emprego formal do país nos últimos anos, tais como: a necessidade de aumentar a arrecadação para amenizar o crescente endividamento público; o aumento da fiscalização referente ao cumprimento da legislação trabalhista e social; a formalização de micro e pequenas empresas, que concentram expressivo número de trabalhadores; e a presença de sindicados, que lutam pelo acesso à seguridade social. (BALTAR et al., 2010; FERNANDES \& CUNHA, 2010; DIEESE, 2012, 2014).

As Políticas governamentais adotadas no decorrer da década de 2000 também influenciaram no movimento evolutivo do estoque de vínculos formais do Brasil. Tais políticas ampliaram o mercado consumidor, fazendo com que as empresas produzissem mais e consequentemente também contratassem mais trabalhadores. Entre essas políticas, podem ser citadas as metas de inflação, a política de valorização do salário mínimo, as políticas de transferência de renda e de expansão do crédito (DIEESE, 2012).

A partir desses diversos fatores motivadores, o mercado formal de trabalho brasileiro vem obtendo patamares crescentes, o que, de acordo com Baltar et al. (2010), ocorreu independentemente de escolaridade, de sexo do trabalhador, de setor de atividade, de tipo de ocupação, de porte de empresa ou de faixa etária, bem como generalizando-se em todas as regiões do Brasil. Diante disso, este artigo dá ênfase ao entendimento de como vem ocorrendo a evolução do estoque de trabalho formal na Região Sul do Brasil e em suas microrregiões.

Para tanto, este trabalho está organizado em quatro seções, além desta introdução. $\mathrm{Na}$ segunda, são apresentadas breves notas sobre o mercado formal de trabalho brasileiro; na terceira, são expostos os procedimentos metodológicos da pesquisa; na quarta são discutidos os resultados obtidos sobre a evolução e qualificação do mercado de trabalho no Sul do Brasil; e, na quinta e última seção, são apresentadas as considerações finais do estudo. 


\section{PROCEDIMENTOS METODOLÓGICOS}

Esta pesquisa refere-se a um estudo descritivo, de abordagem qualitativa, sobre a evolução e qualificação do mercado formal de trabalho do Sul do Brasil. Assim, a área dessa análise foi composta pelos estados do Rio Grande do Sul, Santa Catarina e Paraná, considerando suas microrregiões. O total de microrregiões desses três estados é de 94, subdivididas da seguinte forma: Rio Grande do Sul, com 35; Paraná, com 39; e, Santa Catarina, com 20.

No que tange à coleta de dados, essa foi realizada a partir de dados da RAIS, referentes ao período de 2005 a 2014, envolvendo aspectos como: total de empregos formais; vínculos formais por setores da economia, por sexo do trabalhador, por grau de escolaridade e por faixa de remuneração.

A RAIS é um instrumento de coleta de dados utilizado pela gestão governamental do setor do trabalho brasileiro, instituída pelo Decreto $n^{\circ}$ 76.900, de 23/12/75 (RAIS 2016). Os dados extraídos sobre o mercado de trabalho formal abrangem os empregados Celetistas, Estatutários, Avulsos, Temporários, dentre outros, levando em consideração fatores como a remuneração, o grau de instrução, a ocupação, o sexo e a nacionalidade (MTE, 2016). Assim, a RAIS tem como objetivos: a) o suprimento às necessidades de controle da atividade trabalhista no Brasil; b) o provimento de dados para a elaboração de estatísticas do trabalho; c) a disponibilização de informações sobre o mercado de trabalho às entidades governamentais. Dessa forma, considera-se uma fonte de dados apropriada ao objetivo deste estudo, qual seja: analisar a evolução e a qualificação do mercado formal de trabalho nas microrregiões do Sul do Brasil, entre os anos 2005 e 2014.

Em relação aos setores, para este estudo foram selecionados oito, de acordo com a classificação do IBGE: Extrativa mineral (Ext. min.); Indústria de transformação (Ind. Transf.); Serviços industriais de utilidade pública (Serv. Ind.); Construção Civil (Const. C.); Comércio; Serviços; Administração Pública (Adm. Púb.); e, Agropecuária, extração vegetal, caça e pesca (Agrop.). No que tange à análise dos resultados coletados da RAIS, essa ocorreu de forma descritiva, com o auxílio do Software Excel para a geração de gráficos e tabelas para auxiliar na compreensão.

\section{APONTAMENTOS SOBRE O MERCADO FORMAL DE TRABALHO BRASILEIRO}

A partir do final da década de 1980 e na década de 1990, prevaleceram no mercado de trabalho brasileiro políticas de liberalização e de flexibilização das relações de emprego, com a justificativa que isso criaria e manteria empregos formais e diminuir o quantitativo de empregos informais (MATTEI; VENTURI, 2007; BALTAR et al., 2010). Assim, diversas mudanças ocorreram nas condições de uso e de remuneração do trabalho e nas formas de contratação, tais como: possibilidade de contratação por tempo determinado e por tempo parcial, permissão para a contração temporária de servidos públicos, possibilidade de suspensão dos contratos por um período de até 5 meses, existência do primeiro emprego, entre outros. Contudo, mesmo com tais flexibilizações, o estoque de emprego formal do país não aumentou durante a década de 1990. Os anos 1990, assinalados pela liberalização comercial e financeira externa, pelas privatizações, pela globalização e pelo aumento da produtividade, houve diminuição da demanda de mão de obra (BALTAR et al., 2010; FERNANDES \& CUNHA, 2010). Ou seja, a competitividade gerada pela abertura comercial fez com que 
setores como o da indústria, por exemplo, adotassem novos métodos de produção baseados em tecnologias, diminuindo a necessidade de trabalhadores. Assim, os "resultados de aumento da produtividade do trabalho e da concorrência ocorrem ao custo da redução do emprego" (FERNANDES \& CUNHA, 2010, p. 27).

Esse cenário só passou a se alterar no início do século XXI, pois, a partir de 2004, houve um crescimento do emprego formal. Dados da RAIS (2015) mostram uma evolução dos postos formais de trabalho ao revelarem que, em 2005, o total de vínculos formais era de 33.238.617, enquanto que em 2014, esse número chegou a 49.571.510, ou seja, um crescimento de $49,14 \%$ em termos nominais. Em termos de taxa de crescimento médio anual, o percentual foi de $4,54 \%$.

Ao se considerar apenas o ano de 2014, segundo relatório do Ministério do Trabalho e Emprego - MTE (2016), com base nos dados da RAIS de 2014, constata-se que no Brasil houve um aumento na quantidade de trabalhadores formais em relação ao ano anterior, com um número absoluto de 623.077 novas contratações (o equivalente a uma variação relativa de 1,27\%). Isso pode ser visualizado da Figura 1.

A partir da Figura 1, nota-se que no ano de 2014, exceto no Estado do Amazonas onde decresceu o número de vínculos formais, todos os outros estados brasileiros obtiveram aumento na quantidade absoluta de empregos formais. Essa elevação, conforme o Dieese (2012), deveu-se especialmente ao crescimento da economia brasileira com regularidade. Assim, se o mercado de trabalho brasileiro, em 1990, foi atingido por políticas de liberalização e flexibilização das relações de trabalho para amenizar o desemprego e a precarização do trabalho (MATTEI; VENTURI, 2007), a partir da década de 2000, essas medidas governamentais se tornaram ausentes, de maneira que o resultado econômico nacional positivo, especialmente no que se refere ao Produto Interno Bruto (PIB), tornou-se o principal responsável pela maior geração de empregos formais no Brasil (DIEESE, 2012). Ou seja, há uma relação direta entre desempenho econômico e estoque de emprego formal, de maneira que, quando o país passa por uma elevação no seu PIB, o número de vínculos formais tende a aumentar.

Figura 1 - Saldo do emprego formal (2014) nos estados brasileiros - variação absoluta

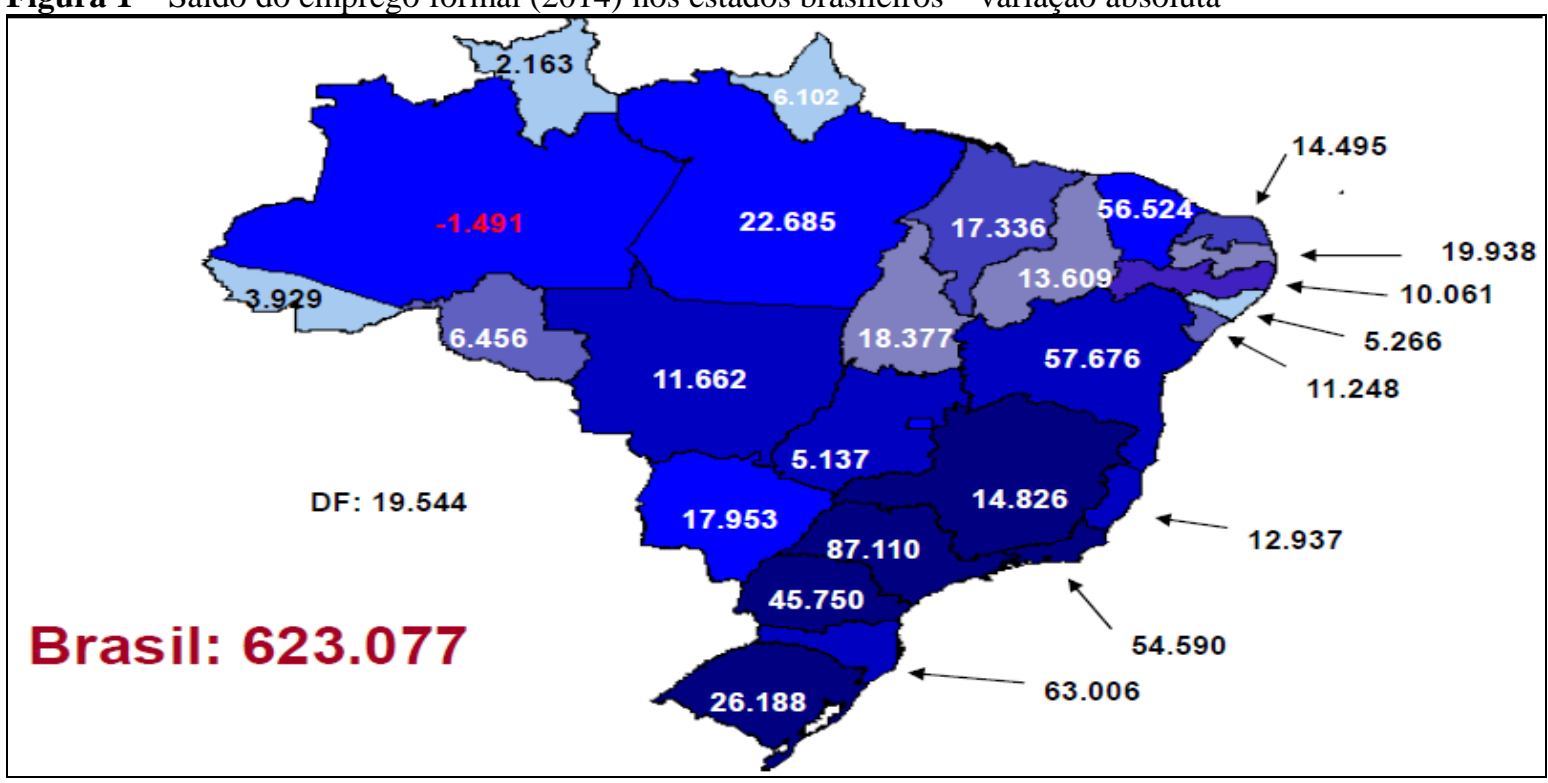

Fonte: MTE (2016) 
Todavia, essa relação entre desempenho econômico e estoque de emprego formal não pode ser considerada estática, pois um aumento/diminuição do PIB não é o único fator responsável pela alteração (para mais ou para menos) do estoque de trabalho formal de um país (DIEESE, 2012). Toma-se o caso, por exemplo, do ano de 2014, quando a taxa de crescimento do PIB foi de $0,1 \%$ em relação ao ano anterior, enquanto que a variação relativa do emprego formal foi de 1,27\% (MTE, 2016). Por conseguinte, torna-se importante ressaltar que, apesar da trajetória de crescimento do estoque de trabalhadores formais do Brasil nos últimos anos, percebe-se um crescimento menor em 2014, quando se compara com anos anteriores, porém houve um crescimento ainda maior do que a taxa de crescimento do PIB.

Nesse sentido, cabe citar que diversas políticas governamentais adotadas no decorrer da década de 2000 têm influenciado para o cenário positivo do emprego formal brasileiro. Entre tais políticas, podem ser citadas: estabelecimento de metas de inflação, valorização do salário mínimo, transferência de renda, expansão do crédito, entre outras. Isso tudo, somado às transformações do mundo do trabalho (mais empregos formais e aumento de renda) "foram, ao mesmo tempo, causa e efeito do processo de crescimento econômico do Brasil" (DIEESE, 2012, p. 16). Assim, o aumento do salário mínimo, por exemplo, fortaleceu o mercado consumidor nacional, que, por sua vez, estimulou as indústrias a produzirem mais e a contratarem mais, elevando o patamar de empregos formais.

Em vista disso, o aumento generalizado dos vínculos formais de trabalhos no Brasil ocorreu concomitantemente ao crescimento da população ocupada com rendimentos, a recuperação da renda média do trabalho e do crescimento da quantidade total de rendas do trabalho (BALTAR et al., 2010). Dessa forma, o aumento de PFT ocorreu independentemente de escolaridade, de sexo ou de faixa etária do trabalhador, bem como ocorreu em todas as regiões do Brasil. Logo, neste artigo, dá-se ênfase à dinâmica da evolução dos empregos formais no Sul do Brasil e em suas respectivas microrregiões.

\section{EVOLUÇÃO E QUALIFICAÇÃO DO EMPREGO FORMAL NA REGIÃO SUL DO BRASIL}

O mercado formal de trabalho no Sul do Brasil tem apresentado evolução crescente na última década, conforme observado na Figura 2. Percebe-se que anualmente ocorreu um aumento no total de postos formais de trabalho (PFT), que totalizavam 5.554.939, em 2005, e 8.118.2015, no ano de 2014. Caso se considere a taxa de crescimento, chega-se à conclusão de que ela foi de $46,14 \%$ nesse período, obtendo uma taxa de crescimento médio anual de $4,31 \%$. Esse crescimento seguiu o cenário nacional, uma vez que a década analisada pode ser considerada uma das mais positivas no que tange à geração de vínculos formais de trabalho no Brasil (DIEESE, 2012; 2014), com uma taxa de crescimento médio anual de 4,54\%.

Figura 2 - Total de PFT no Sul do Brasil - PR, SC e RS (2005-2014) 


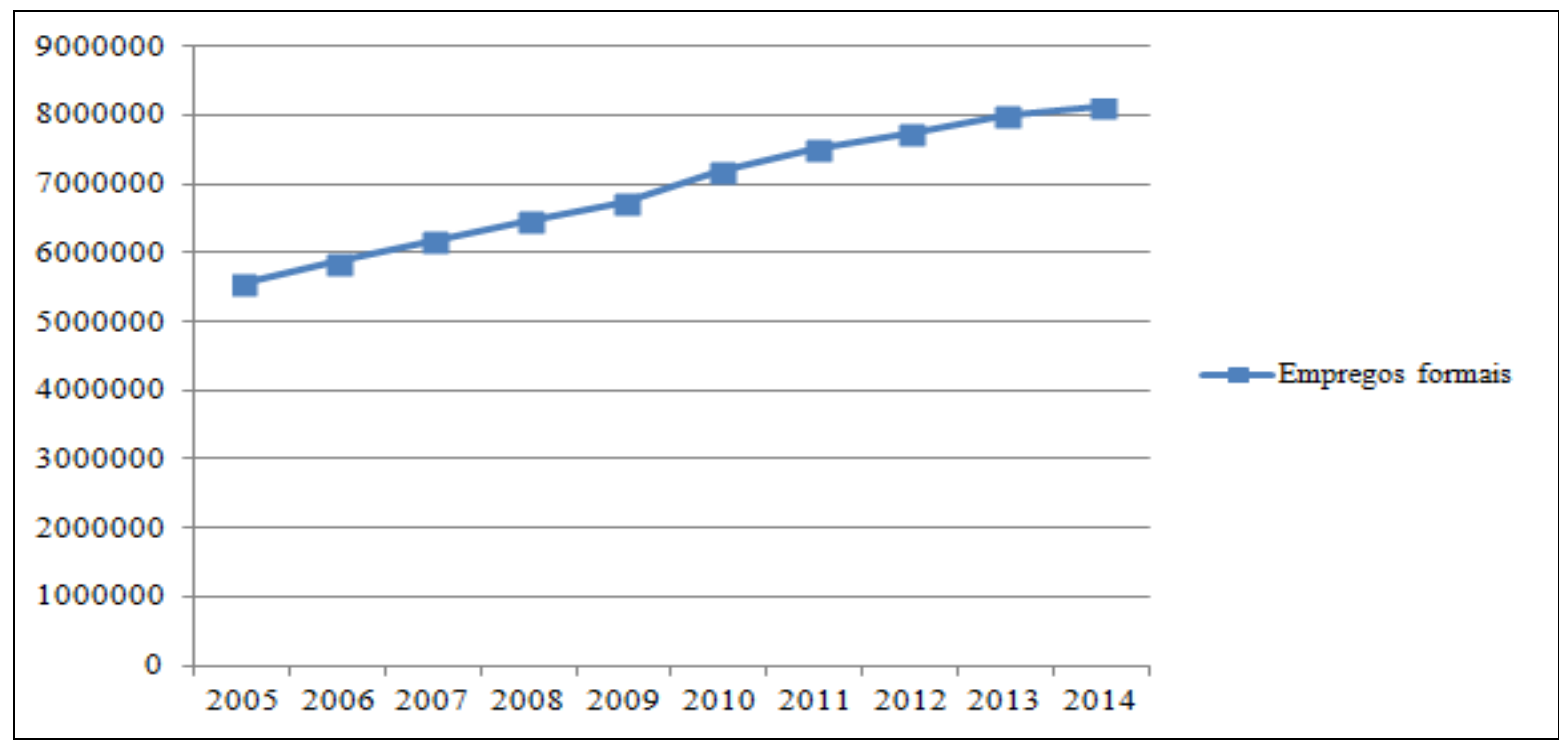

Fonte: elaboração própria a partir de dados da RAIS/MTE (2016)

Entre as possíveis justificativas para o crescente aumento do número de PFT, segundo Baltar et al. (2010) e Dieese (2012), pode ser citada a favorável dinâmica macroeconômica do Brasil nesse período, principalmente no que se refere ao positivo crescimento Produto Interno Bruto (PIB) do país. Isso quer dizer que a dinâmica do PIB tem correlação direta com a dos empregos formais. Contudo, cabe ressaltar que essa correlação não é estática, pois, em 2009, por exemplo, mesmo com a queda do PIB brasileiro (em função da crise internacional), a quantidade de vínculos formais de trabalho continuou a aumentar. Isso ocorreu, conforme Dieese (2012), em função de isenções de impostos federais sobre produtos industrializados, que mantiveram a demanda por tais produtos em alta, de medidas direcionadas à manutenção ou elevação na oferta de empréstimos e financiamentos bancários a pessoas físicas e jurídicas, de pacote habitacional, entre outros fatores que resultaram no aumento do estoque de emprego formal.

Além da questão macroeconômica, outros fatores conduziram à evolução de PFT no Brasil e consequentemente na Região Sul. É o caso de fatores e políticas governamentais que caracterizaram a década de 2000, tais como: as metas de inflação, a política de valorização do salário mínimo, as políticas de transferência de renda e de expansão do crédito, a maior fiscalização do cumprimento da legislação do trabalho, a maior pressão das entidades sindicais (BALTAR et al., 2010; DIEESE, 2012). Tais políticas ampliaram o mercado consumidor, que induziu as organizações a produzirem mais e a contratarem mais, influenciando positivamente na taxa de crescimento dos vínculos formais de trabalho dos últimos anos.

Outra questão que favoreceu a evolução no número de empregos formais do Brasil e na Região Sul do país refere-se às condições institucionais e legais que envolvem a formalização do emprego. Ou seja, se na década de 1990 políticas de liberalização e flexibilização das relações de trabalho eram motivadas para amenizar o desemprego e a precarização do trabalho, a partir de 2000, a crescente evolução dos PFT sem a aprovação e a presença de tais políticas demonstra que as mesmas não são mais responsáveis pelo saldo positivo de empregos formais (MATTEI \& VENTURI, 2007; DIEESE, 2012). Ademais, esse crescimento do número de empregos formais se deu de maneira ampla e generalizada, independentemente de região, se metropolitana ou se interiorana, de faixa etária, de nível de escolaridade, de faixa de remuneração e de setores da economia (BALTAR et al., 2010). Em 
termos regionais, conforme Dieese (2014), a Região Sudeste é a que mais concentra empregos formais, seguida das regiões Nordeste e Sul.

Em relação aos estados da Região Sul, quais sejam: Paraná (PR), Santa Catarina (SC) e Rio Grande do Sul (RS), cabe ressaltar que todos eles tiveram crescimento dos PFT em todos os anos analisados (2005 a 2014). Os estados do Paraná e Rio Grande do Sul possuíam quantidades aproximadas de empregos formais no decorrer do período, superiores àquelas de Santa Catarina. Todavia, em 2005, o Paraná possuía 2.109.348 postos formais de trabalho, enquanto que o Rio Grande do Sul tinha uma quantidade maior, um total de 2.235.468. Já em 2014, o primeiro detinha 3.167.134 e o segundo 3.109.179 vínculos formais, ou seja, desde 2012, o Paraná possui maior estoque de trabalhadores formais do que o outro estado. Entre as possíveis justificativas, podem estar os investimentos realizados pelo Estado do Paraná, desde a metade da década de 1990, para a instalação de novas empresas, ampliações e modernizações das empresas já existentes, intensificando a diversificação e a modernização do perfil produtivo (FERNANDES; CUNHA, 2011).

Em relação a Santa Catarina, do total de 1.210.123 vínculos, em 2005, passou para 1.841.905 em 2014. Porém, cabe ressaltar que esse foi o estado com a maior taxa de crescimento no período em análise, com 52,21\%. Em seguida, vem o Paraná, com 50,15\%, e depois o Rio Grande do Sul, com 39,08\%. Levando-se em consideração as taxas de crescimento médio anual desses três estados, têm-se os percentuais de 4,78\%, 4,62\% e 3,73\%, respectivamente.

Em uma análise por microrregiões do Sul do Brasil, o primeiro aspecto a se ressaltar é que todas as 94 aumentaram o quantitativo de empregos formais no período de 2005 a 2014 , de forma que todas obtiveram positivas taxas de crescimento médio anual. Em estudo anterior, sobre a distribuição regional do emprego formal no Sul do Brasil (2000 a 2005), Alves e Ferrera de Lima (2005) também já apontavam o aumento em números absolutos do emprego formal na região em estudo, enfatizando o crescimento em todas as mesorregiões. Neste trabalho, em função da quantidade de microrregiões, optou-se por relacionar na Tabela 1 apenas as $10 \mathrm{com}$ as maiores e as menores taxas de crescimento médio anual (2005 a 2014). Como se pode observar, Pato Branco, no Paraná, é a microrregião com o maior percentual de criação de postos formais de trabalho no período (7,11\% a.a) e São Bento do Sul, em Santa Catarina, foi a de menor percentual de crescimento (1,04\% a.a.).

Ao observar-se mais atentamente, é possível perceber que entre as 10 microrregiões com as menores taxas de crescimento médio anual, cinco delas são do Estado do Paraná, duas de Santa Catarina e três do Rio Grande do Sul, mas todas com índices positivos. Já em relação às 10 microrregiões com os maiores índices de crescimento médio anual, cinco pertencem ao estado de Santa Catarina (Itajaí, Ituporanga, Chapecó e Tijucas); três, ao Paraná (Pato Branco, Francisco Beltrão e Wenceslau Braz); e, três ao Rio Grande do Sul (Frederico Westphalen, Não-Me-Toque e Sananduva). Um aspecto relevante a acrescentar é o fato de que o número de habitantes dos municípios que compõe essas microrregiões ser baixo. Ao serem considerados, por exemplo, todos os municípios que compõem as três primeiras microrregiões da Tabela 1 (Pato Branco-PR, composta por 10 municípios; Itajaí-SC, composta por 12 municípios; Ituporanga-SC, composta por sete municípios), apenas quatro deles possuem mais do que 50.000 habitantes, conforme dados do Censo Demográfico 2010, do Instituto Brasileiro de Geografia e Estatística - IBGE (2016a); e, além disso, todos estão localizados no Estado de Santa Catarina, a saber: Balneário Camboriú, Itajaí e Navegantes.

Tabela 1 - Ranking das dez microrregiões com maiores e menores taxas de crescimento médio anual de postos formais de trabalho- Região Sul do Brasil (2005 a 2014)

$$
\text { Posição }
$$

Microrregião

Tx. \% a. a 


\begin{tabular}{cll}
\hline $1^{\circ}$ & Pato Branco - PR & $7,11 \%$ \\
$2^{\circ}$ & Itajaí - SC & $6,94 \%$ \\
$3^{\circ}$ & Ituporanga - SC & $6,68 \%$ \\
$4^{\circ}$ & Frederico Westphalen - RS & $6,52 \%$ \\
$5^{\circ}$ & Francisco Beltrão - PR & $6,27 \%$ \\
$6^{\circ}$ & Não-Me-Toque - RS & $6,18 \%$ \\
$7^{\circ}$ & Chapecó - SC & $6,17 \%$ \\
$8^{\circ}$ & Tijucas - SC & $6,06 \%$ \\
$9^{\circ}$ & Wenceslau Braz - PR & $5,81 \%$ \\
$10^{\circ}$ & Sananduva - RS & $5,76 \%$ \\
- & & \\
$85^{\circ}$ & Joaçaba - SC & $2,99 \%$ \\
$86^{\circ}$ & Floraí - PR & $2,99 \%$ \\
$87^{\circ}$ & Serras de Sudeste - RS & $2,91 \%$ \\
$88^{\circ}$ & Gramado-Canela - RS & $2,85 \%$ \\
$89^{\circ}$ & Três Passos - RS & $2,69 \%$ \\
$90^{\circ}$ & Jaguariaíva - PR & $2,22 \%$ \\
$91^{\circ}$ & Palmas - PR & $2,02 \%$ \\
$92^{\circ}$ & Cerro Azul - PR & $1,82 \%$ \\
$93^{\circ}$ & Ibaiti - PR & $1,29 \%$ \\
$94^{\circ}$ & São Bento do Sul - SC & $1,04 \%$ \\
\hline
\end{tabular}

Fonte: elaboração própria a partir de dados da RAIS/MTE (2016)

A trajetória de crescimento do estoque de empregos formais tem se dado, mormente, e de maneira mais acelerada, em municípios de pequeno porte, isto é, naqueles com até 49,9 mil habitantes, revelando a interiorização do emprego formal brasileiro (DIEESE, 2012; 2014). Alves e Ferrera de Lima (2005), ao analisarem as mesorregiões do Sul do Brasil, igualmente observaram que as regiões do interior vêm ampliando a capacidade de gerar postos formais de trabalho, mais do que as regiões metropolitanas, demonstrando um possível fortalecimento da economia urbana das regiões interioranas. Dessa forma, a realidade apresentada para as microrregiões do Sul do Brasil, em relação às com maiores taxas de crescimento médio anual de empregos formais, é a mesma que está ocorrendo em âmbito nacional.

Após a análise da evolução dos empregos formais no Sul do Brasil, no período 20052014, foram identificados outros fatores, tais como: classificação dos postos formais de trabalho segundo setores da economia, segundo o sexo, segundo a escolaridade e segundo a faixa de remuneração.

Na Figura 3 é apresentada a quantidade de PFT em cada ano da análise (2005-2014) e em cada setor, sendo possível constatar que, ao longo do período, a maior concentração de empregos está principalmente nos setores de indústria da transformação e de serviços, seguidos do de comércio. Em termos absolutos, o setor de serviços gerou 932.623 vínculos formais no período de 2005 a 2014: saiu de 1.574.570 empregos, em 2005, e atingiu o patamar de 2.507.193, em 2014, ou seja, uma taxa de crescimento de 59,24\% no período. Já o setor de indústria da transformação, que possuía, em 2005, 1.578 .740 empregos formais, no final de 2014, empregava 2.097.837, o que equivale a uma taxa de crescimento de 32,88\%. No que tange ao setor de comércio, esse apresentava, em 2005, 1.080.912 postos formais de 
trabalho, enquanto que, em 2014, tinha 1.705.025 vínculos, revelando uma taxa de crescimento de $57,7 \%$.

Figura 3 - Total de postos formais de trabalho, segundo setores de atividade, no Sul do Brasil (2005-2014)

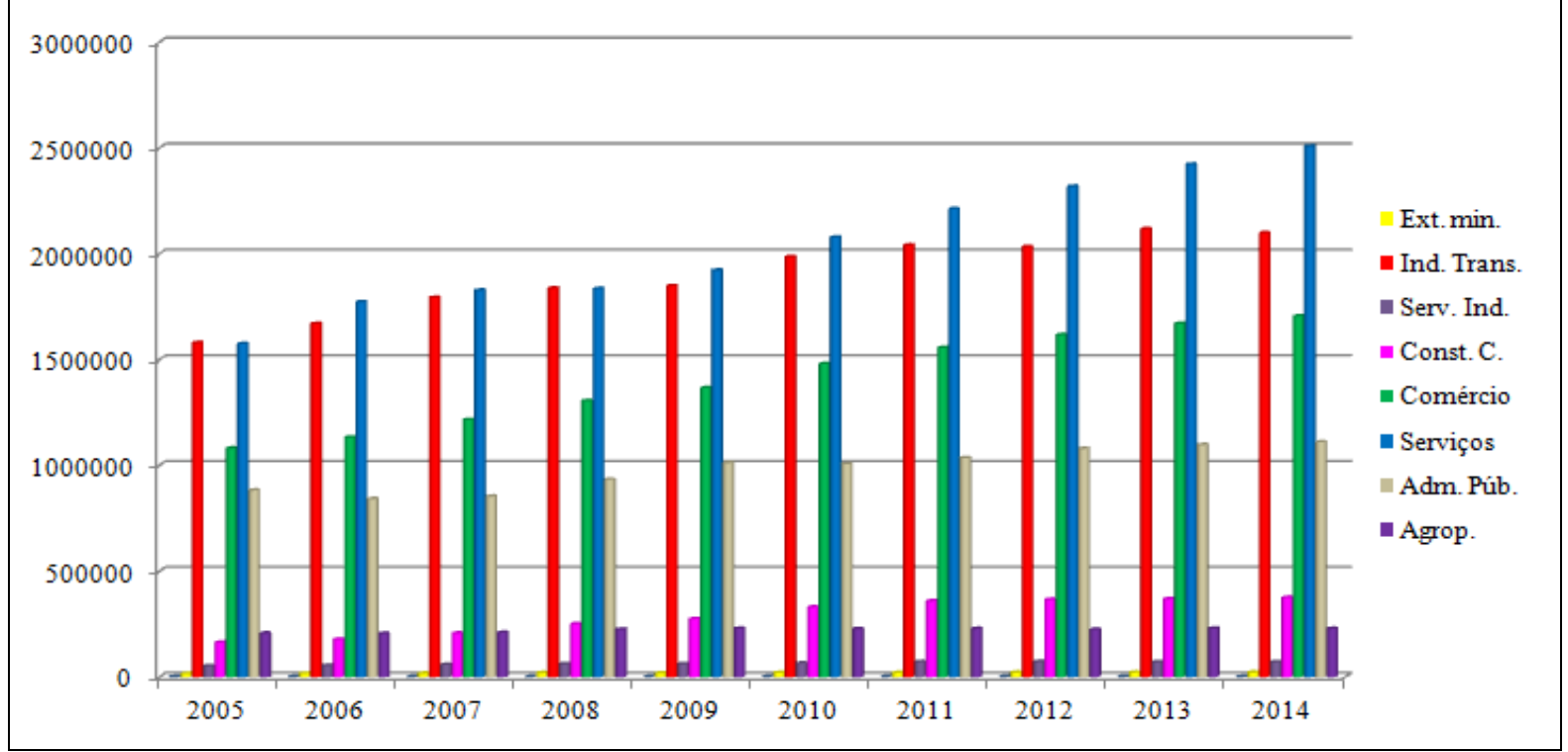

Fonte: elaboração própria a partir de dados da RAIS/MTE (2016)

Em termos de taxa de crescimento médio anual desses três setores, o da indústria de transformação teve um crescimento médio de 3,21\% a.a. (com decréscimos nos anos de 2012 e 2014, em relação aos anos 2011 e 2013); o de comércio obteve aumento de 5,19\% a.a.; e o de serviços cresceu 5,31\% a.a. Não obstante, cabe observar que o setor de serviços evoluiu de maneira crescente em todos os anos, juntamente com o setor de comércio. Dessa forma, é possível afirmar que o setor terciário tem sido o que mais emprega na região Sul do Brasil.

Alves e Ferrera de Lima (2005) já mencionavam uma elevação do número de empregos formais no setor terciário em todo o Sul do Brasil (no período de 2000 a 2005), somada também ao aumento de vínculos formais das indústrias tradicionais e dinâmicas. Em 2014, o setor de serviços foi responsável por $31 \%$ dos postos formais de trabalho, o que significa um aumento de sua participação relativa, já que, em 2005, isso era de 28,34\%. Já o setor de indústria da transformação obteve um decréscimo na sua participação relativa, uma vez que, em 2005, possuía 28,42\% dos empregos formais, e, em 2014, apresentou $26 \%$. O setor de comércio aumentou sua representatividade, pois no primeiro ano da análise teve participação de 19,46\% do total de empregos formais e, em 2014, de $21 \%$.

O crescimento da participação relativa dos setores de serviços e de comércio na região Sul do Brasil não é diferente da realidade brasileira. Essa também é a ordem caso se considere a criação de PFT no Brasil, em números absolutos, especialmente depois de 2004. Isso pode ser consequência de fatores como o fortalecimento gradativo do mercado interno consumidor, que a partir da manutenção de baixas taxas de inflação, de acesso ao crédito, de valorização do salário mínimo, de programas de transferência de renda e de investimentos públicos em infraestrutura e habitação, têm possibilitado aos consumidores a aquisição de diversos bens, o que, por sua vez, fortalece os setores de serviços e de comércio (DIEESE, 2012).

Em relação ao setor de indústria de transformação, cabe dizer que a queda da sua participação relativa se deveu pela elevada incorporação de novas tecnologias, ou seja, nos últimos anos, o ferramental tecnológico adotado pelas indústrias tem eliminado a necessidade 
de contratação de mão de obra, deixando de criar vínculos formais de trabalho (BALTAR et al., 2010; DIEESE, 2012).

Ao serem focados outros setores, o de extrativismo mineral, em números absolutos, detinha 15.751 postos formais de trabalho, em 2005, e 22.038, em 2014, aumentando sua participação de $0,27 \%$ para $0,28 \%$ no período. A construção civil, que era responsável, em 2005, por 163.498 vínculos formais, chega, em 2014, a 375.680, passando sua participação relativa de $2,94 \%$ para $4 \%$. O setor de administração pública, no último ano analisado, apresentou 1.110 .428 empregos formais, o que equivale a 14\% de participação relativa. Já em 2005 , o número absoluto de vínculos era de 881.889 , o que representava $15,88 \%$. Por sua vez, a agropecuária, por mais que aumentou o número de empregos formais no período 2005-2014, de 207.237 para 228.595 , diminuiu sua representatividade, de $3,73 \%$, no primeiro ano da análise, para 2,82\% do total de postos formais de trabalho do Sul do Brasil em 2014.

A partir da análise da divisão dos empregos formais do Sul do país por setores, a partir daqui se volta o olhar para cada estado individualmente e para as microrregiões. Para tanto, na Tabela 2, demonstra-se a taxa média de crescimento anual dos PFT, segundo setores de atividade econômica, por estado da Região Sul do Brasil (2005 a 2014).

Tabela 2 - Taxa média de crescimento anual dos PFT, segundo setores da economia, por estado (2005 a 2014)

\begin{tabular}{l|rrr}
\hline \multicolumn{1}{c|}{ Setores } & PR & SC & RS \\
\hline Extrativismo mineral & $4,52 \%$ & $2,54 \%$ & $4,72 \%$ \\
Indústria de Transformação & $3,94 \%$ & $3,73 \%$ & $2,13 \%$ \\
Serviços Industriais de Utilidade Pública & $2,89 \%$ & $4,20 \%$ & $3,72 \%$ \\
Construção Civil & $\mathbf{1 1 , 7 9 \%}$ & $\mathbf{9 , 6 1 \%}$ & $\mathbf{7 , 8 1 \%}$ \\
Comércio & $\mathbf{5 , 2 2 \%}$ & $\mathbf{5 , 4 0 \%}$ & $\mathbf{5 , 0 5 \%}$ \\
Serviços & $\mathbf{5 , 2 3 \%}$ & $\mathbf{5 , 7 0 \%}$ & $\mathbf{5 , 2 0 \%}$ \\
Administração Pública & $2,95 \%$ & $\mathbf{5 , 0 0 \%}$ & $1,55 \%$ \\
Agropecuária, extração vegetal, caça e pesca & $1,35 \%$ & $0,29 \%$ & $1,23 \%$ \\
\hline Fon
\end{tabular}

Fonte: elaboração própria a partir de dados da RAIS/MTE (2016)

Comparando a Tabela 2 com os dados apresentados anteriormente, percebe-se que, apesar dos setores de serviço, de comércio e de indústria de transformação terem as maiores taxas de participação relativa nos PFT do Sul do Brasil, é o setor de construção civil que possui a maior taxa de crescimento médio anual de vínculos formais de trabalho, nos três estados: Paraná $(11,79 \%)$, Santa Catarina $(9,61)$ e Rio Grande do Sul $(7,81 \%)$. Esse setor é seguido pelo de serviços e de comércio.

Voltando a atenção para as microrregiões, foi possível constatar que, comparando-se o número de microrregiões com taxas positivas de crescimento médio anual em cada setor, de fato a maioria delas estava localizada nos setores de construção civil, de serviços e de comércio, mas apareceu também a administração pública. Ou seja, nos outros setores, uma quantidade maior de microrregiões obteve índices negativos de crescimento médio anual.

Com base nesse critério (maior número de microrregiões com taxas positivas de crescimento médio anual), optou-se por elencar as 10 microrregiões que possuem as maiores taxas de crescimento médio anual nos setores de construção civil, de serviços e de comércio (Tabela 3). Nesta análise, os percentuais de crescimento médio anual do setor de administração pública não foram expostos por serem menores do que os três setores ora citados. Todavia, ressalva-se que, entre as 10 microrregiões com os mais elevados índices de crescimento médio anual do setor de administração pública, seis pertencem ao Estado de Santa Catarina, o que vem ao encontro da alta taxa de crescimento desse setor no referido 
Estado (5\%) quando comparada com os outros dois estados da região Sul (conforme apresentado na Tabela 2).

O setor de construção civil possui os maiores índices de crescimento médio anual quando comparado aos outros dois setores (Tabela 3). Além disso, percebe-se que um número maior de microrregiões do Estado do Paraná aparece quando se consideram os setores de construção civil e de comércio, ou seja, das 10 microrregiões apresentadas em cada setor, sete são do Paraná. Entre as explicações para essa notoriedade do comércio no Paraná pode estar a expansão da demanda por bens de consumo depois do Plano Real, motivada pelo aumento de crédito das pessoas físicas decorrente da estabilidade da economia nacional. Já em relação à construção civil, entre as justificativas podem ser citadas políticas de âmbito federal, tais como: o Programa de Aceleração de Crescimento (PAC), Brasil Maior e Minha Casa Minha Vida, que motivaram a geração de empregos em todo o Brasil (FERNANDES \& CUNHA, 2011; CARDOSO, 2013).

Tabela 3 - Dez microrregiões do Sul do Brasil com as maiores taxas crescimento médio anual de postos formais de trabalho (construção civil, serviços e comércio) (2005-2014)

\begin{tabular}{|c|c|c|c|c|c|}
\hline $\begin{array}{l}\text { Microrregião } \\
\text { Construção } \\
\end{array}$ & $\begin{array}{l}\text { Tx a.a. } \% \\
\text { ivil }\end{array}$ & $\begin{array}{l}\text { Microrregião } \\
\text { Comércio }\end{array}$ & Tx a.a. $\%$ & $\begin{array}{cc}\text { Microrregião } & \text { T } \\
\text { Serviços } & \\
\end{array}$ & Tx a.a. $\%$ \\
\hline Tabuleiro-SC & $31,92 \%$ & Cerro Azul-PR & $9,50 \%$ & Capanema-PR & $10,13 \%$ \\
\hline Porecatu-PR & $28,86 \%$ & Campo Mourão-PR & $9,00 \%$ & Sananduva-RS & $9,48 \%$ \\
\hline Goioerê-PR & $27,70 \%$ & Pitanga-PR & $8,81 \%$ & Chapecó-SC & $8,96 \%$ \\
\hline Camaquã-RS & $26,03 \%$ & Wenceslau Braz-PR & $8,78 \%$ & Santa Maria-RS & $8,93 \%$ \\
\hline Telêmaco Borba-PR & $24,78 \%$ & Palmas-PR & $8,43 \%$ & Lapa-PR & $8,03 \%$ \\
\hline Capanema-PR & $22,65 \%$ & Frederico Westphalen-RS & $8,39 \%$ & Osório-RS & $8,00 \%$ \\
\hline Prudentópolis-PR & $22,18 \%$ & Tijucas-SC & $7,85 \%$ & Ituporanga-SC & $7,94 \%$ \\
\hline $\begin{array}{l}\text { União da Vitória- } \\
\text { PR }\end{array}$ & $21,57 \%$ & Goioerê-PR & $7,57 \%$ & Frederico Westphalen-RS & $7,75 \%$ \\
\hline Curitibanos-SC & $21,34 \%$ & Guaporé-RS & $7,45 \%$ & Cerro Largo-RS & $7,74 \%$ \\
\hline Faxinal-PR & $20,59 \%$ & Lapa-PR & $7,36 \%$ & Pato Branco-PR & $7,66 \%$ \\
\hline
\end{tabular}

Fonte: elaboração própria a partir de dados da RAIS/MTE (2016)

De maneira geral, a realidade constatada para as microrregiões do Sul do Brasil em termos de crescimento médio anual de empregos formais, nos setores de construção civil, de comércio e de serviços, também ocorre em todo o Brasil. Segundo o Dieese (2012) esses setores têm obtido as mais elevadas taxas de crescimento em termos de geração de PFT, o que decorre, pelo menos em parte, de uma economia que vem se caracterizando pelo consumo de massa e por investimentos em infraestrutura. Dessa forma, a recuperação e aumento do número de empregos formais ocorrem em setores nos quais, geralmente, os salários são mais baixos, como é o caso do comércio e da construção civil (BALTAR et al., 2010; DIEESE, 2012).

Finalizada a análise sobre os postos formais de trabalho em cada um dos setores, outro fator a ser considerado é o sexo. Nesse sentido, na Tabela 4 são expostas as quantidades de trabalhadores registrados segundo o sexo.

O primeiro aspecto a ser mencionado, ao observar a Tabela 4, é o visível aumento da participação da mulher no mercado de trabalho, pois se os postos de trabalho ocupados pelas mesmas representavam 41,68\% em 2005, no ano de 2014, esse percentual aumentou para $45,17 \%$. Por outro lado, a participação masculina diminuiu de $58,32 \%$ para $54,83 \%$ nesse período. Ademais, percebe-se que a taxa de crescimento médio anual de empregos formais femininos foi maior do que a masculina, respectivamente de $5,24 \%$ e $3,59 \%$. 
O crescimento da participação feminina no mercado de trabalho da Região Sul do Brasil já foi apontado em estudo de Martini et al. (2011), sobre a inserção produtiva feminina nas atividades produtivas da Região Sul do período de 1996 a 2006. As justificativas apontadas por esses autores para esse cenário foram: a queda das taxas de fecundidade, o aumento das famílias nas quais a mulher é responsável pela manutenção econômica, os novos papéis desenvolvidos pelas mulheres, o aumento dos anos de escolaridade e a alteração no modelo tradicional de família. Isso tudo não é diferente da realidade brasileira, conforme apontado pelo Dieese (2012), que acrescenta às justificativas anteriores para a crescente participação feminina: a emancipação econômica da mulher, a busca da realização profissional, a oportunidade de atuação em diversas áreas de trabalho, a possibilidade de atuar nas diferentes esferas públicas de poder e em postos de trabalho anteriormente reservados somente para homens. Porém, é necessário lembrar que as transformações ainda não indicam igualdade de oportunidades e de participação entre homem e mulher; e ainda diversas mudanças são necessárias para maior inclusão da mulher no mercado de trabalho e na sociedade.

Tabela 4 - Distribuição dos PFT, segundo sexo, no Sul do Brasil (2005 a 2014)

\begin{tabular}{rrrrrr}
\hline & Masculino & \% & Feminino & \% & Sul do Brasil \\
\hline 2005 & 3239585 & 58,32 & 2315354 & 41,68 & 5554939 \\
2006 & 3387592 & 57,72 & 2481696 & 42,28 & 5869288 \\
2007 & 3566372 & 57,69 & 2615291 & 42,31 & 6181663 \\
2008 & 3697592 & 57,19 & 2768267 & 42,81 & 6465859 \\
2009 & 3810932 & 56,60 & 2921989 & 43,40 & 6732921 \\
2010 & 4061405 & 56,47 & 3130337 & 43,53 & 7191742 \\
2011 & 4230077 & 56,23 & 3292089 & 43,77 & 7522166 \\
2012 & 4283286 & 55,41 & 3446232 & 44,59 & 7729518 \\
2013 & 4415654 & 55,22 & 3580814 & 44,78 & 7996468 \\
2014 & 4451544 & 54,83 & 3666674 & 45,17 & 8118218 \\
\hline
\end{tabular}

Fonte: elaboração própria a partir de dados da RAIS/MTE (2016)

Assim, mesmo sendo crescente a parcela de mulheres no mercado de trabalho, essa ainda é bem inferior à dos homens. Enquanto esses possuíam participação relativa de 54,83\%, em 2014, as mulheres correspondiam $45,17 \%$ dos empregos formais, situação que se torna mais preocupante caso se considere que a população brasileira é composta em sua maioria por mulheres (51\%), conforme dados do Censo Demográfico de 2010 (IBGE, 2016b). Assim, segundo Santos e Aruto (2012), a menor participação da mulher no mercado formal de trabalho brasileiro é ainda influenciada por fatores culturais, especialmente no que tange ao direcionamento de atividades chamadas de convencionais quase que apenas para as mulheres, como os afazeres domésticos. Tais atividades são muitas vezes informais e, portanto, não contabilizadas no estoque de emprego formal.

Em uma análise por setores, chega-se a conclusão que a indústria da transformação do Sul do Brasil ainda é o setor que absorve o maior número de trabalhadores masculinos, um total de 1.317.479, em 2014. Considerando que no ano de 2005, esse número era de 1.045.806, chega-se a uma taxa de crescimento de 25,98\% no período. Em termos de participação relativa, em 2005, do total de postos formais de trabalhos ocupados por homens, $32,28 \%$ era absorvido por esse setor; e, em 2014, esse percentual passou ser de 29,6\%, sendo possível entender que houve uma redistribuição dos empregos para outros setores. O setor de 
serviços também se destaca na quantidade de trabalhadores formalmente vinculados, haja vista que, em 2014, possuía 27,9\% (o equivalente, em números absolutos, a 1.241.767 homens) do total de postos formais de trabalho ocupados pelo sexto masculino enquanto que em 2005 essa participação era de 25,9\% (com 839.514 empregos formais).

Já, ao considerar o setor com a maior taxa de crescimento de empregos formais masculinos, é preciso citar o de construção civil. Isso porque o percentual aumentou $124,4 \%$ entre 2005 e 2014. No primeiro ano analisado, o total absoluto de postos formais de trabalhos ocupados por homens nesse setor era de 153.914 e atingiu a quantidade de 345.378 em 2014 . Os setores de serviço e comércio também se destacam quando se fala em taxa de crescimento no período (2005-2014), pois cresceram 47,91\% e 44,66\%, respectivamente. Porém, quando se analisar os setores que possuem a maior participação de homens no total de empregados, em 2014, podem ser citados: extrativismo mineral, 91,95\%; construção civil, 91,93\%; serviços industriais de utilidade pública, 80,80\%; e agropecuária, 79,77\%.

No que tange ao sexo feminino, os setores com as maiores taxas de participação das mulheres são: administração pública, 66,25\%; serviço, 50,47\%; e comércio, 46,52\%. Há que se destacar, por isso, que em apenas dois setores o sexo feminino possui maior participação relativa ao total de postos formais de trabalhos, quais sejam, os já citados, administração pública e serviços.

Martini et al. (2011) igualmente relataram a maior participação feminina nos setores de administração pública, de serviços e de comércio do Sul do Brasil, entre 1996 e 2006. Todavia, naqueles anos, os serviços representavam a maior presença da mulher em comparação aos outros dois setores, ao contrário do cenário de 2005 a 2014. Essa é a realidade, segundo Dieese (2012), também do Brasil, pois desde a década de 2000, as mulheres têm sido maioria entre os servidores públicos. Porém, cabe dizer que quando se relaciona emprego formal feminino e esfera de poder público, há números diferentes. Referente o ano de 2009, por exemplo, na esfera federal, a maioria dos PFT $(64,9 \%)$ era composto por homens, enquanto que, nas esferas estaduais e municipais, a maioria era formada por mulheres, $57,1 \%$ e $64 \%$, respectivamente.

Já a maior presença da mulher no setor de serviços, conforme o Dieese (2012), pode ser explicada porque historicamente algumas funções relacionadas ao cuidado da família e da moradia são atribuídas ao sexo feminino, o que resultou, ao longo do tempo, na atuação de muitas mulheres no setor de serviços pessoais, como a alimentação, a educação e a saúde.

Em termos de setores que mais empregam mulheres, em números absolutos, encontra-se o setor de serviços, que atingiu, em 2014, um total de 1.265.426 postos de trabalho. Posteriormente, o setor de indústria da transformação, com um total absoluto de 793.244 postos de trabalho em 2014. Nesse mesmo ano, o comércio e a administração pública seguem em terceiro e quarto lugar entre os setores com mais pessoas do sexo feminino, possuindo 780.358 e 735.608 empregadas, respectivamente. Considerando as taxas de crescimento de postos de trabalho feminino no período em análise (2005-2014), destaca-se o da construção civil, que aumentou $216,17 \%$, pois, em 2005 , atingia a quantidade absoluta de 9.584 postos de trabalho femininos; e, em 2014, possuía 1.265.426.

Fazendo uma análise por microrregiões do Sul do Brasil, observou-se que todas as 94 obtiveram percentuais positivos de crescimento médio anual de PFT ocupados pelas mulheres entre 2005 e 2014. Nesse mesmo período, em termos de empregos formais masculinos, apenas uma microrregião, a de Ibaiti (PR), apresentou redução da taxa média anual $(-0,11 \%$ a.a) de trabalhadores homens. Contudo, ao comparar as taxas de crescimento médio anual de PFT ocupados por homens e mulheres, apresentam-se índices mais elevados para a ocupação feminina, conforme pode ser observado na Tabela 5. Em função da quantidade de microrregiões, são apresentadas nessa tabela apenas as 10 microrregiões com as maiores taxas 
de crescimento médio anual de PFT, tanto para homens quanto para mulheres, a fim de melhor visualizar a diferença de percentuais.

É possível visualizar que, enquanto o maior índice de crescimento médio anual de empregos formais ocupados por homens é de 6,50\% a.a. (microrregião de Frederico Westphalen-RS), o das mulheres chega a 8,57\% a.a. (microrregião de Pato Branco-PR). Ao considerar-se as 94 microrregiões, em 19 delas essa determinada taxa de empregos formais femininos é superior a 6,50\% a.a., que é o mais alto percentual de crescimento médio anual de PFT masculinos. Porém, ao analisar-se os números absolutos de vínculos formais femininos e masculinos, no ano de 2014, apenas uma das 94 microrregiões possui maior número de mulheres do que homens no mercado formal de trabalho, que é o caso de Floraí-PR. Nessa microrregião, o ano de 2014 terminou com 2.818 mulheres e 2.759 homens. Todas as outras microrregiões possuem mais PFT de trabalho masculinos do que femininos.

Tabela 5 - Dez microrregiões com as maiores taxas crescimento médio anual de PFT masculinos e femininos (2005-2014)

\begin{tabular}{ll|ll}
\hline \multicolumn{1}{c|}{$\begin{array}{c}\text { Microrregião } \\
\text { Feminino }\end{array}$} & \multicolumn{1}{c}{ Tx a.a. \% } & \multicolumn{1}{c}{$\begin{array}{c}\text { Microrregião } \\
\text { Masculino }\end{array}$} & \multicolumn{1}{c}{ Tx a.a. \% } \\
\hline Pato Branco-PR & $8,57 \%$ & Frederico Westphalen-RS & $6,50 \%$ \\
Itajaí-SC & $7,80 \%$ & Ituporanga-SC & $6,49 \%$ \\
Fernandópolis-SC & $7,78 \%$ & Itajaí-SC & $6,28 \%$ \\
Joinville-SC & $7,52 \%$ & Não-Me-Toque-RS & $6,16 \%$ \\
Sananduva-RS & $7,41 \%$ & Pato Branco-PR & $6,01 \%$ \\
Chapecó-SC & $7,29 \%$ & Francisco Beltrão-PR & $5,99 \%$ \\
Ituporanga-SC & $6,91 \%$ & Pitanga-PR & $5,82 \%$ \\
Santa Rosa-RS & $6,87 \%$ & Tijucas-SC & $5,68 \%$ \\
Foz do Iguaçu-PR & $6,78 \%$ & Litoral Lagunar-RS & $5,45 \%$ \\
Paranaguá-PR & $6,74 \%$ & Capanema-PR & $5,43 \%$ \\
\hline
\end{tabular}

Fonte: elaboração própria a partir de dados da RAIS/MTE (2016)

Voltando à Tabela 5, microrregiões de Santa Catarina são as que aparecem em maior número (cinco) entre as 10 com maior crescimento médio anual de empregos formais femininos. Mattei e Venturi (2007) e Santos e Aruto (2012) comentaram esse cenário ao apontarem que as diferenças entre a força de trabalho feminina e masculina vêm diminuindo expressiva e paulatinamente no decorrer do tempo nas mais diversas regiões desse estado. Isso teria ocorrido especialmente em função de expressivas taxas de reemprego, ou seja, mulheres que já tinham algum vínculo formal e posteriormente foram contratadas por outro empregador; e também pela possível busca crescente do primeiro emprego por mulheres.

Depois da análise sobre o sexo, a escolaridade se torna foco. $\mathrm{Na}$ Tabela 6, é apresentada a distribuição dos empregos formais, segundo o grau de escolaridade, no Sul do Brasil no período 2005-2014.

O primeiro aspecto que chama a atenção é em relação às taxas de crescimento médio anual dos ocupados que possuem 12 anos ou mais de estudo, ou seja, com ensino médio completo, superior incompleto e superior completo, cujas taxas são de $8,36 \%$ a.a., 3,84\% a.a e $8,15 \%$ a.a, respectivamente. Por outro lado, observa-se que os postos formais de trabalho ocupados por indivíduos analfabetos ou com até nove anos de estudo tem diminuído entre 2005 e 2014. Por exemplo, o analfabetismo diminuiu a uma taxa média anual de $1,83 \%$ no período, enquanto que até a quinta série completa decresceu $4,44 \%$ ao ano. 
Em termos de participação relativa, os postos formais de trabalho que tiveram sua participação mais elevada foram os ocupados por indivíduos com ensino médio completo (de $30,75 \%$ de participação relativa em 2005 assumiram o percentual de 43,34\% em 2014) e com ensino superior completo (de 12,67\% em 2005, para 17,55\% em 2014). Ao serem somados esses percentuais, a participação relativa dos empregos ocupados por pessoas com ensino superior incompleto, tem-se a seguinte situação: em 2005, os empregados com ensino médio completo, superior incompleto e superior completo representavam 48,34\% do total de postos formais de trabalho; em 2014, esse índice alcança 65,61\%.

Tabela 6 - Distribuição dos PFT, segundo grau de escolaridade, no Sul do Brasil (2005 a 2014)

\begin{tabular}{llllllllllll}
\hline Ano & $\begin{array}{l}\text { Analfa- } \\
\text { beto }\end{array}$ & $\begin{array}{l}\text { Até } \\
\text { Incomp. }\end{array}$ & $\begin{array}{l}\mathbf{5}^{\mathbf{a}} \text { Comp. } \\
\text { Fund. }\end{array}$ & $\begin{array}{l}\mathbf{6}^{\mathbf{a}} \mathbf{a}^{\mathbf{a}} \\
\text { Fund. }\end{array}$ & \multicolumn{1}{l}{$\begin{array}{l}\text { Fund. } \\
\text { Comp. }\end{array}$} & \multicolumn{1}{l}{$\begin{array}{l}\text { Médio } \\
\text { Incomp. }\end{array}$} & $\begin{array}{l}\text { Médio } \\
\text { Comp. }\end{array}$ & \multicolumn{2}{l}{$\begin{array}{l}\text { Sup. } \\
\text { Incomp. }\end{array}$} & $\begin{array}{l}\text { Sup. } \\
\text { Comp. }\end{array}$ & \multicolumn{1}{l}{ Total } \\
\hline 2005 & 22660 & 206158 & 387394 & 704672 & 971762 & 577019 & 1708425 & 272919 & 703930 & 5554939 \\
2006 & 21753 & 195458 & 369839 & 695607 & 986201 & 592140 & 1921939 & 293037 & 793314 & 5869288 \\
2007 & 23811 & 212200 & 361751 & 703183 & 1010512 & 631988 & 2076818 & 304928 & 856472 & 6181663 \\
2008 & 22374 & 200993 & 350254 & 692414 & 1018899 & 633658 & 2312342 & 324564 & 910361 & 6465859 \\
2009 & 22437 & 198721 & 330130 & 663108 & 1010358 & 634922 & 2524737 & 344614 & 1003894 & 6732921 \\
2010 & 22061 & 212033 & 324564 & 678716 & 1041898 & 672984 & 2813914 & 365408 & 1060164 & 7191742 \\
2011 & 18156 & 218604 & 316199 & 675924 & 1042777 & 692793 & 3049684 & 381215 & 1126814 & 7522166 \\
2012 & 17561 & 212790 & 291104 & 651788 & 1020212 & 697742 & 3225316 & 383846 & 1229159 & 7729518 \\
2013 & 18776 & 215388 & 278633 & 639959 & 1011000 & 710556 & 3428612 & 387133 & 1306411 & 7996468 \\
2014 & 19189 & 206690 & 257392 & 622133 & 979102 & 707696 & 3518369 & 383152 & 1424495 & 8118218 \\
\hline $\mathbf{a . a}$. & & & & & & & & & & \\
$\mathbf{\%}$ & $\mathbf{- 1 , 8 3 \%}$ & $\mathbf{0 , 0 3 \%}$ & $\mathbf{- 4 , 4 4 \%}$ & $\mathbf{- 1 , 3 7 \%}$ & $\mathbf{0 , 0 8 \%}$ & $\mathbf{2 , 2 9 \%}$ & $\mathbf{8 , 3 6 \%}$ & $\mathbf{3 , 8 4 \%}$ & $\mathbf{8 , 1 5 \%}$ & $\mathbf{4 , 3 1 \%}$ \\
\hline
\end{tabular}

Fonte: elaboração própria a partir de dados da RAIS/MTE (2016)

Dessa forma, é possível entender que está havendo uma maior qualificação do mercado formal de trabalho no Sul do Brasil, nos últimos anos. De acordo com o Dieese (2014), nos últimos anos aparece evidenciada uma trajetória de elevação do nível de instrução formal dos trabalhadores do Brasil, especialmente se considerar o número de vínculos formais de trabalhos que vêm sendo mais ocupados por indivíduos com ensino médio completo e com ensino superior completo. Igualmente aos resultados obtidos para o Sul do Brasil, os analfabetos e com menos anos de estudo têm diminuído nos últimos anos. Ainda para o Dieese (2012), esse cenário tem sido consequência, por um lado, de uma demanda cada vez maior de profissionais mais qualificados; e, por outro lado, pelo esforço de escolarização buscado pelos próprios trabalhadores. Assim, dois principais fatores podem justificar o aumento do número de trabalhadores formais qualificados, quais sejam: a maior escolaridade média da população brasileira, principalmente das mulheres, e uma contratação mais seletiva, por meio da exigência de conhecimento de novos procedimentos organizacionais. Ocorre então uma forma de barreira aos trabalhadores com pouca escolaridade, fazendo com que os anos de estudos aumentassem entre os vínculos formais de trabalho dos últimos anos. Dessa maneira, acredita-se em um cenário positivo em âmbito nacional e também para o Sul do Brasil, em termos de qualificação da mão de obra formal para os próximos anos.

Ao se comparar os empregos formais segundo o grau de escolaridade e os setores econômicos, percebe-se que alguns setores se caracterizam por uma maior qualificação dos empregados em relação aos outros. Esse é o caso, por exemplo, do setor de Administração Pública, que, em 2014, teve a maior concentração de vínculos formais de trabalho ligada a faixas de alta escolaridade, ou seja, com ensino superior incompleto e completo. As taxas de participação dessas faixas de escolaridade foram de $3,37 \%$ e $51,40 \%$, respectivamente, ou 
seja, mais da metade dos empregados desse setor estão cursando uma faculdade ou já a cursaram. Em números absolutos, em 2014, esse setor abarcava 570.714 empregos formais no Sul do Brasil.

Esse cenário não é único da Região Sul do Brasil (DIEESE, 2012), uma vez que a escolaridade dos servidores públicos tem aumentado em âmbito nacional (nas esferas municipal, estadual e federal), por motivos diversos, tais como: própria iniciativa do colaborador, que busca melhoria no plano de carreira, e o aumento na exigência dos concursos públicos.

É relevante destacar que todos os outros setores (em 2014) possuíam a maior participação relativa de vínculos formais de trabalho concentrada na faixa de escolaridade de ensino médio completo, a saber:

a) Comércio: $57,08 \%$

b) Serviços: $43,25 \%$

c) Indústria da Transformação: $42,65 \%$

d) Serviços Industriais: 41,62\%

e) Construção Civil: $39,65 \%$

f) Extração Mineral: $38,49 \%$

g) Agropecuária: 25,30\%

Os Serviços e os Serviços Industriais, mesmo que ainda concentrassem a maior quantidade de empregados com ensino médio completo, foram os que mais se destacaram (depois do setor de Administração Pública) em índices de empregados com ensino superior completo ou que estivessem cursando. Em 2014, 22,25\% dos empregados do setor de Serviços Industriais já tinham encerrado o curso de graduação, enquanto que 4,06\% estavam ainda cursando. Por sua vez, o setor de Serviços, em 2014, concentrava 21,96\% de vínculos com ensino superior completo e $6,45 \%$ que ainda estavam cursando.

Entre os setores que acumulavam empregos com faixas de escolaridade mais baixas (até o ensino fundamental completo) estão: Agropecuária $(62,15 \%)$, Construção Civil (45,32\%) e Extração Mineral (44,51\%). Em número absoluto, esses setores acumulavam, conjuntamente, 322.237 vínculos formais ocupados por empregados que possuíam apenas o ensino fundamental completo, ou seja, ainda não possuíam ensino médio, em 2014.

$\mathrm{Na}$ análise das 94 microrregiões do Sul do Brasil, constatou-se que praticamente todas elas apresentaram elevação nas taxas de crescimento médio anual de PFT ocupados por trabalhadores com um maior grau de escolaridade, isto é, com ensino médio completo, superior incompleto e superior completo. Em relação ao ensino médio completo, as 94 microrregiões tiveram elevação das taxas de crescimento médio anual de vínculos formais, ocupados por indivíduos com esse nível de escolaridade, sendo o maior percentual o da microrregião de Ituporanga-SC (13,81\% a.a.) e o menor percentual o da microrregião de Porto Alegre-RS (6,12\% a.a.). Já no que tange ao ensino superior incompleto, apenas duas microrregiões obtiveram índices negativos de crescimento médio anual de empregos formais ocupados por trabalhadores com esse grau de escolaridade, a saber: Floraí-PR (-0,51\% a.a.) e Tabuleiro-SC (-3,97\% a.a.). Por sua vez, sobre os PFT ocupados por trabalhadores com ensino superior completo, cabe dizer que apenas uma microrregião, a de Porecatu-PR, obteve uma pequena redução da taxa de crescimento médio anual, de $-0,13 \%$ a.a. Todas as outras também tiveram seus índices aumentados, sendo que o maior deles (crescimento de 14,99\% a.a) foi da microrregião de Sananduva-RS. A partir disso, foram elencadas as 10 microrregiões com as maiores taxas de crescimento médio anual de PFT, ocupados por trabalhadores com nível de escolaridade alto (ensino médio completo, superior incompleto e superior completo) na Tabela 7. 
Observa-se que entre as 10 microrregiões com índices mais elevados de trabalhadores com ensino superior completo, sete são do Estado do Paraná. Enquanto isso, microrregiões de Santa Catarina são maioria quando se trata do ensino médio completo e do ensino superior incompleto. A elevação do número de trabalhadores formais com ensino superior nas diversas microrregiões do Paraná poderia ser explicada, pelo menos em parte, como consequência da inserção e proliferação de faculdades privadas nesse estado, principalmente a partir do início da década de 2000 (CIMBALISTA, 2007). Tais instituições de ensino vêm ofertando inúmeros cursos de graduação a fim de suprir a necessidade de qualificação dos trabalhadores.

Em relação às microrregiões de Santa Catariana, ao serem comparados os resultados do estudo de Mattei e Venturi (2007), sobre a escolaridade para o estado como um todo, podese entender que o cenário de elevação do nível de escolaridade, desde 2005 (último ano de análise do referido estudo), até 2014, continuou ocorrendo. Mattei e Venturi (2007) identificaram que, entre 1991 e 2005, um expressivo percentual de trabalhadores formais de Santa Catarina já estava cursando o ensino médio ou o tinham completado. Nos últimos anos, entre 2005 e 2014, ganharam destaque os percentuais de trabalhadores com ensino médio completo e que já estão cursando o ensino superior.

Tabela 7 - Dez microrregiões com as maiores taxas de crescimento médio anual dos PFT, com alto nível de escolaridade (2005 a 2014)

\begin{tabular}{lr|ll|lc}
\multicolumn{1}{c|}{$\begin{array}{c}\text { Micrroregião } \\
\text { Ensino Médio Completo }\end{array}$} & \multicolumn{1}{c|}{$\begin{array}{c}\text { Tx a.a. \% } \\
\text { Ensino Superior Incompleto }\end{array}$} & \multicolumn{1}{c}{$\begin{array}{c}\text { Micrroregião } \\
\text { Tx a.a. \% }\end{array}$} & $\begin{array}{c}\text { Micrroregião } \\
\text { Ensino Superior Completo }\end{array}$ & $\begin{array}{c}\text { Tx a.a. \% } \\
\text { Ituporanga-SC }\end{array}$ \\
Curitibanos-SC & $13,81 \%$ & Cerro Azul-PR & $14,67 \%$ & Sananduva-RS & $14,99 \%$ \\
Litoral Lagunar-RS & $13,33 \%$ & Jaguarão-RS & $14,49 \%$ & Rio Negro-PR & $14,67 \%$ \\
Itajaí-SC & $13,05 \%$ & Rio Negro-PR & $11,46 \%$ & Cerro Azul-PR & $14,33 \%$ \\
Araranguá-SC & $12,41 \%$ & Serras de Sudeste-RS & $10,37 \%$ & Lapa-PR & $14,00 \%$ \\
Tabuleiro-SC & $12,27 \%$ & Ituporanga-SC & $9,84 \%$ & Prudentópolis-PR & $14,00 \%$ \\
Osório-RS & $11,92 \%$ & Não-Me-Toque-RS & $9,63 \%$ & Tabuleiro-SC & $13,85 \%$ \\
Chapecó-SC & $11,56 \%$ & Chapecó-SC & $8,34 \%$ & Chapecó-SC & $13,72 \%$ \\
União da Vitória-PR & $11,40 \%$ & Tijucas-SC & $8,01 \%$ & Francisco Beltrão-PR & $13,41 \%$ \\
Pato Branco-PR & $11,37 \%$ & Capanema-PR & $7,82 \%$ & Capanema-PR & $13,37 \%$ \\
\hline
\end{tabular}

Fonte: elaboração própria a partir de dados da RAIS/MTE (2016)

O último aspecto analisado neste estudo foi a faixa de remuneração dos postos formais de trabalho, entre 2005 e 2014, que é apresentada na Tabela 8. Conforme Mattei e Venturi (2007), os rendimentos são importantes para a qualidade de vida dos trabalhadores e por isso essa variável deve ser analisada. Nesse sentido, observou-se que, na região Sul do Brasil, a maior parte $(69,79 \%)$ dos empregados recebeu entre um e três salários mínimos (ano de 2014), atingindo um total de 5.665.799 pessoas. Ao serem considerados os que receberam, em 2014, de meio salário até cinco salários mínimos, chega-se ao percentual de 87,26\%, totalizando 7.083.741 trabalhadores.

Ao comparar esses percentuais com o ano de 2005, tem-se um cenário muito semelhante, uma vez que os empregados que recebiam de um e três salários mínimos representavam 65,67\% (3.647.953 trabalhadores), enquanto que, se fossem somados todos os que recebiam entre meio a cinco salários mínimos, esse percentual era de 84,92\% (4.717.375 trabalhadores). Ocorreu um pequeno aumento no número de empregados que passaram a 
receber entre cinco e quinze salários mínimos; em 2005, esse total era de 665.278 empregados e, em 2014, correspondia a 749.787 trabalhadores.

Pode-se visualizar que as taxas de crescimento médio anual tiveram elevação nas faixas de remuneração mais baixas, quais sejam: um a um e meio salário mínimo (6,31\% a.a.); meio a um salário mínimo (5,67\% a.a.); e até meio salário mínimo $(5,65 \%)$. Porém, as taxas percentuais de trabalhadores com rendimentos entre 15 e 20 salários mínimos e com mais de 20 salários mínimos diminuíram no período analisado, $-0,87 \%$ a.a e $-2,94 \%$ a.a, respectivamente.

Se considerar o já exposto anteriormente sobre o fato de que a recuperação e aumento do número de empregos formais ocorrem em setores nos quais os salários são mais baixos, como é o caso do comércio e da construção civil (BALTAR et al. 2010; DIEESE, 2012), essa pode ser uma das justificativas para o aumento do número de PFT com faixas de remuneração mais baixas. Além disso, cabe observar que a taxa de crescimento médio anual das faixas de remuneração mais baixas (até dois salários mínimos) cresceu em patamares mais elevados do que a própria taxa de crescimento médio anual do estoque de empregos formais, ou seja, enquanto essa última aumentou $4,31 \%$ a.a. no período de 2005 a 2014 , as faixas salariais de zero até meio salário mínimo, de meio até um salário mínimo, de um até um e meio salário mínimo e de um meio até dois salários mínimos cresceram, respectivamente, $5,65 \%$ a.a., $5,67 \%$ a.a., $6,31 \%$ a.a., $4,71 \%$ a.a.

Em uma análise por setores da economia, os que apresentam PFT com maiores faixas de rendimentos são os Serviços Industriais e a Administração Pública. Em 2014, mais de um quarto $(25,73 \%)$ dos empregados da Administração Pública receberam mais do que cinco salários mínimos. Mas, caso se somem os trabalhadores que obtiveram rendimentos acima de três salários mínimos, o total chega a quase à metade $(49,74 \%)$. Os Serviços Industriais, em 2014, possuíam 38,36\% dos empregados formais recebendo acima de cinco salários mínimos e 59,68\% deles tinham rendimentos acima de três salários mínimos.

Em relação aos setores com piores remunerações, podem ser citados a Agropecuária e o Comércio, isso porque 66,55\% dos empregados do Comércio receberam até dois salários mínimos em 2014, enquanto que 68,41\% dos da Agropecuária receberam essa faixa de rendimento nesse mesmo ano.

$\mathrm{Na}$ análise por microrregiões, o primeiro aspecto a se destacar é que todas as 94 microrregiões tiveram elevação da taxa de crescimento médio anual de PFT remunerados em até dois salários mínimos e em até cinco salários mínimos. Quando considerar a remuneração de até cinco salários mínimos, por exemplo, a microrregião de Pato Branco é que apresentou o maior índice de crescimento médio anual (7,21\% a.a), enquanto que Ibaiti-PR obteve a menor taxa de crescimento médio anual (1\% a.a.). Essa realidade não foi constatada quando considerada a remuneração acima de cinco salários mínimos. Por exemplo, quando se analisa a faixa de remuneração de cinco até 15 salários mínimos, 32 das 94 microrregiões apresentaram índices negativos de crescimento médio anual. Nesse caso, a maior taxa foi da microrregião de Cerro Azul-PR (7,50\% a.a) e a menor foi da microrregião de Três Passos-RS $(3,08 \%$ a.a. $)$. 
Tabela 8 - Distribuição dos PFT, segundo faixa remuneração, no Sul do Brasil (2005 a 2014)

\begin{tabular}{|c|c|c|c|c|c|c|c|c|c|c|c|}
\hline . & 2005 & 2006 & 2007 & 2008 & 2009 & 2010 & 2011 & 2012 & 2013 & 2014 & Tx a.a. $\%$ \\
\hline Até $\mathbf{0 , 5 0}$ & 19308 & 21223 & 21908 & 24010 & 26430 & 30591 & 30550 & 32215 & 32197 & 31671 & $5.65 \%$ \\
\hline $\begin{array}{l}0,51 \text { a } \\
1,00\end{array}$ & 162453 & 182627 & 199500 & 213155 & 233353 & 250429 & 246400 & 267491 & 270928 & 266850 & $5.67 \%$ \\
\hline $\begin{array}{l}1,01 \text { a } \\
1,50\end{array}$ & 105684 & 1522186 & 1708312 & 1811870 & 2020294 & 2139952 & 1995883 & 2174239 & 2122385 & 1917575 & $6.31 \%$ \\
\hline $\begin{array}{l}1,51 \text { a } \\
2,00\end{array}$ & 1282972 & 1286122 & 1334533 & 1396943 & 1438933 & 1587268 & 1713327 & 1748098 & 1837701 & 1941299 & $4.71 \%$ \\
\hline $\begin{array}{l}2,01 \text { a } \\
3,00\end{array}$ & 1259297 & 1226149 & 1260850 & 1320512 & 1341330 & 1424171 & 1590553 & 1584682 & 1701678 & 1806925 & $4.09 \%$ \\
\hline $\begin{array}{l}3,01 \text { a } \\
4,00\end{array}$ & 560759 & 539424 & 548391 & 570811 & 571920 & 590685 & 661964 & 657252 & 693035 & 744493 & $3.20 \%$ \\
\hline $\begin{array}{l}4,01 \text { a } \\
5,00\end{array}$ & 326902 & 300038 & 292849 & 300158 & 296425 & 307928 & 334758 & 331184 & 350983 & 374928 & $1.53 \%$ \\
\hline $\begin{array}{l}5,01 \text { a } \\
7,00\end{array}$ & 320232 & 293986 & 299404 & 302396 & 290084 & 308268 & 342532 & 336734 & 360659 & 380485 & $1.93 \%$ \\
\hline \begin{tabular}{|l}
7,01 a \\
10,00
\end{tabular} & 211159 & 190683 & 190982 & 193129 & 179443 & 190921 & 209487 & 204745 & 218409 & 225141 & $0.71 \%$ \\
\hline $\begin{array}{l}10,01 \text { a } \\
15,00\end{array}$ & 133887 & 123613 & 120491 & 118899 & 114498 & 120501 & 133165 & 129727 & 137165 & 144161 & $0.82 \%$ \\
\hline $\begin{array}{l}15,01 \text { a } \\
20,00\end{array}$ & 59528 & 56607 & 54347 & 54940 & 48935 & 50228 & 53114 & 51219 & 52298 & 55030 & $-0.87 \%$ \\
\hline $\begin{array}{l}\text { Mais de } \\
20,00\end{array}$ & 72246 & 62564 & 58128 & 59286 & 53867 & 54604 & 59061 & 51549 & 52460 & 55222 & $-2.94 \%$ \\
\hline Total & 5554939 & 5869288 & 6181663 & 6465859 & 6732921 & 7191742 & 7522166 & 7729518 & 7996468 & 8118218 & $4.31 \%$ \\
\hline
\end{tabular}

Fonte: elaboração própria a partir de dados da RAIS/MTE (2016) 
Na Tabela 9 são mostradas as 10 microrregiões que obtiveram as taxas de crescimento médio anual mais elevadas e as 10 menos elevadas, subdividindo as faixas de remuneração da seguinte forma: uma análise das faixas até cinco salários mínimos e uma análise das faixas de cinco a quinze salários mínimos.

Tabela 9 - Dez microrregiões com as maiores e as menores taxas de crescimento médio anual de PFT, com faixas de remuneração até cinco salários mínimos e de cinco a quinze salários mínimos (2005 a 2014)

\begin{tabular}{lc|lr}
\hline \multicolumn{1}{c}{$\begin{array}{c}\text { Microrregião } \\
\text { Até 5 salários mínimos }\end{array}$} & Tx a.a \% & \multicolumn{2}{c}{$\begin{array}{c}\text { Microrregião } \\
\text { De 5 a 15 salários mínimos }\end{array}$} \\
\hline Pato Branco-PR & $7,21 \%$ & Cerro Azul-PR & $7,50 \%$ \\
Itajaí-SC & $7,14 \%$ & Campanha Meridional-RS & $5,45 \%$ \\
Frederico Westphalen-PR & $6,73 \%$ & Chapecó-SC & $5,23 \%$ \\
Ituporanga-SC & $6,65 \%$ & Itajaí-SC & $5,19 \%$ \\
Não-Me-Toque-RS & $6,32 \%$ & Litoral Lagunar-RS & $4,86 \%$ \\
Francisco Beltrão-PR & $6,20 \%$ & Capanema-PR & $4,61 \%$ \\
Foz Do Iguaçu-PR & $6,17 \%$ & Pato Branco-PR & $4,58 \%$ \\
Chapecó-SC & $6,03 \%$ & Tijucas-SC & $4,58 \%$ \\
Litoral Lagunar-RS & $6,02 \%$ & Umuarama-PR & $4,47 \%$ \\
Paranaguá-PR & $5,94 \%$ & Francisco Beltrão-PR & $4,23 \%$ \\
$\ldots$ & $\ldots$ & $\ldots$ & $\ldots$ \\
Floraí-PR & $3,03 \%$ & Montenegro-RS & $-1,28 \%$ \\
Três Passos-RS & $3,02 \%$ & Cornélio Procópio-PR & $-1,43 \%$ \\
Serras de Sudeste-RS & $2,96 \%$ & Paranaguá-PR & $-1,62 \%$ \\
Joaçaba-SC & $2,86 \%$ & Campos de Lages-SC & $-1,66 \%$ \\
Gramado-Canela-RS & $2,85 \%$ & Cachoeira do Sul-RS & $-1,90 \%$ \\
Jaguariaíva-PR & $2,62 \%$ & Santa Cruz do Sul-RS & $-1,99 \%$ \\
Palmas-PR & $1,93 \%$ & Jaguariaíva-PR & $-2,18 \%$ \\
São Bento do Sul-SC & $1,52 \%$ & Campanha Ocidental-RS & $-2,73 \%$ \\
Cerro Azul-PR & $1,51 \%$ & São Bento do Sul-SC & $-2,95 \%$ \\
Ibaiti-PR & $1,00 \%$ & Três Passos-RS & $-3,08 \%$ \\
\hline Fon & & &
\end{tabular}

Fonte: elaboração própria a partir de dados da RAIS/MTE (2016)

Observando as taxas médias de crescimento anual em ambas as faixas salariais, torna-se evidente a presença de taxas mais altas na faixa até cinco salários mínimos do que de cinco a 15 salários mínimos. Entre as explicações para esse cenário pode ser citado que, a partir de 2003, o Brasil tem passado por um movimento positivo em relação ao salário mínimo (SM) gerando impactos também positivos sobre o mercado de trabalho nas mais diversas regiões do país (CARDOSO JR.; MUSSE, 2014). Diante disso, não apenas o número de postos formais de trabalho aumentou, mas, também, mais trabalhadores passaram a ser remunerados. Logo, ainda segundo Cardoso Jr. e Musse (2014 p. 17), “é possível valorizar o SM e ainda assim ver crescer a ocupação geral, inclusive a formalização dos vínculos de emprego".

A partir desses aspectos referentes à remuneração dos postos formais de trabalho, encerra-se a análise da evolução e da qualificação do mercado formal de trabalho da Região Sul do Brasil e de suas microrregiões, restando ainda tecer algumas considerações finais. 


\section{CONCLUSÃO}

O objetivo deste estudo foi analisar a evolução e a qualificação do mercado formal de trabalho no Sul do Brasil e em suas respectivas microrregiões. Foram utilizados dados da RAIS/MTE para o período de 2005 a 2014, a fim de verificar a evolução do emprego formal em termos de: setores da economia, sexo do trabalhador, grau de escolaridade e faixa de remuneração.

Pelos resultados, percebeu-se que a Região Sul do Brasil passou por uma evolução crescente do número de postos formais de trabalho, situação resultante de diversos fatores. Entre eles, pode ser citada a dinâmica macroeconômica que o Brasil tem apresentado nos últimos anos, especialmente com a estabilidade monetária e com retomada do crescimento econômico, a partir de 2004, o que motivou a formalização do trabalho. Além disso, a adoção de políticas públicas voltadas a metas de inflação, valorização do salário mínimo, transferência de renda, expansão do crédito, entre outras, também influenciaram no aumento dos empregos formais no Sul do Brasil. Em termos regionais, foi possível constatar que todas as 94 microrregiões do Sul do país obtiveram positivas taxas de crescimento médio anual de vínculos formais de trabalho, merecendo destaque as microrregiões de Pato Branco-PR, ItajaíSC, Ituporanga-SC e Frederico Westphalen-RS, com índices de crescimento acima de 6,5\% a.a.

Em relação aos setores, os serviços, a indústria de transformação e o comércio assumiram destaque no quantitativo de empregos formais do Sul do Brasil e em suas microrregiões, ao longo do período analisado. Todavia, foi o setor de construção civil que demonstrou as maiores taxas de crescimento médio anual entre 2005 e 2014, nos três estados: Paraná, Santa Catarina e Rio Grande do Sul. Observa-se que aumentaram os PFT em setores cuja remuneração geralmente é baixa, como no comércio e na construção civil.

No que tange ao sexo do trabalhador, foi possível observar o aumento da participação da mulher no mercado formal de trabalho, inclusive com taxas de crescimento médio anual em todas as 94 microrregiões do Sul do Brasil e em índices maiores do que os dos homens. Porém, sua participação relativa ainda é inferior a do sexo masculino. Em números absolutos, por mais que em muitas microrregiões o número de mulheres seja superior ao de homens, apenas uma apresentou maior quantidade de vínculos formais ocupados pelo sexo feminino. Cabe refletir sobre as questões que ainda dificultam uma maior participação relativa da mulher no mercado formal de trabalho, haja vista que essas no período eram em número maior do que os homens no Brasil. Considerar atividades informais é necessário, mas aspectos culturais, de remuneração, de reconhecimento do trabalho, entre outros aspectos, também devem ser analisados.

Considerando o grau de escolaridade, as microrregiões estudadas têm apresentado PFT mais qualificados nos últimos anos, pois houve crescimento do número de trabalhadores com ensino médio completo, com ensino superior completo ou que estejam ursando. De maneira geral, apenas três microrregiões obtiveram decréscimo dos percentuais relativos à taxa de crescimento médio anual de empregos formais ocupados por indivíduos com os níveis de escolaridade acima citados, ainda assim em índices negativos que podem considerados baixos. Dessa maneira, pode-se compreender que empregadores dos trabalhadores das microrregiões estudadas estão buscando pessoal mais qualificado e de certa forma criando barreiras à entrada de trabalhadores menos qualificados. Isso pode ser considerado positivo sob o olhar da melhor qualificação da mão de obra, porém pode vir a ser um desafio quando pensar em condições de inserção de trabalhadores com menos anos de estudo. 
Em termos de remuneração do trabalho formal, constatou-se que todas as microrregiões do Sul do Brasil apresentaram positivas taxas de crescimento médio anual de vínculos formais remunerados em até dois salários mínimos e em até cinco salários mínimos. A redução dessas taxas ficou por conta de salários mais elevados, de cinco até 15 salários mínimos, por exemplo. Dessa forma, entende-se que, apesar de um maior número de trabalhadores terem acesso a rendimentos, a remuneração dos trabalhadores nas diversas microrregiões estudadas ainda é baixa.

A partir dos resultados do estudo, entende-se que as mais diversas microrregiões analisadas têm passado por um cenário favorável em relação à evolução e à qualificação dos postos formais de trabalho, no período de 2005 a 2014, tanto no que se refere ao maior número de trabalhadores formais e, portanto, com garantia a direitos legais e trabalhistas, quanto no que tange à maior inserção feminina, ao aumento do grau de escolaridade e ao maior número de trabalhadores com remuneração. Contudo, fatores tais como os índices de informalidade ainda persistentes, a discriminação da mulher, a falta de acesso à educação e faixas de remuneração ainda baixas podem entrar na discussão sobre as possíveis melhorias.

Por fim, para pesquisas futuras, sugere-se a análise de outros fatores não abordados neste estudo e que possuem relação com o mercado de trabalho formal, tais como: a faixa etária do trabalhador, a nacionalidade, o tipo de admissão, o tipo de vínculo, o motivo do desligamento entre outros. Ademais, um olhar mais detalhado para a relação entre o sexo do trabalhador, a faixa etária e a faixa de remuneração.

\section{REFERÊNCIAS}

ALVES, Y. B.; FERRERA DE LIMA, J. A distribuição regional do emprego formal no Sul do Brasil. Textos de Economia, Florianópolis, v. 11, n. 2, p. 47-70, 2008.

BALTAR, P. E. A; SANTOS, A. L; KREIN, J. D et al. Trabalho no governo Lula: uma reflexão sobre a recente experiência brasileira. Global Labour University Working Papers, 2010. (Paper, 09). Disponível em: 〈http://www.global-labouruniversity.org/fileadmin/GLU_Working_Papers/GLU_WP_No._9_portuguese.pdf>. Acesso em: 12 fev 2016.

CARDOSO, F. E. Incentivo do estado e desenvolvimento: uma analise sobre o crescimento da área da construção civil. Semana de Ciências Sociais, Universidade Estadual de Londrina.

Anais... 2013.

CARDOSO JR., J. C.; MUSSE, J. S. Salário Mínimo e Desenvolvimento: Desdobramentos de uma política de valorização real no Brasil. Revista Ciências do Trabalho. n. 2, 2014.

CIMBALISTA, S. Mudanças no mercado de trabalho formal no Paraná - 1985-2005. Análise Conjuntural, v.29, n.07-08, p.14, 2007.

DIEESE - Departamento Intersindical de Estatística e Estudos Socioeconômicos. A situação do trabalho no Brasil na primeira década dos anos 2000. São Paulo: DIEESE, 2012. Disponível em: 〈http://www.dieese.org.br/livro/2012/livroSituacaoTrabalhoBrasil.pdf>. Acesso em: 12 fev 2016. 
DIEESE - Departamento Intersindical de Estatística e Estudos Socioeconômicos. O mercado de trabalho formal brasileiro: resultados da RAIS 2013. Nota Técnica, 2014. Disponível em: $<$ http://www.dieese.org.br/notatecnica/2014/notaTec140Rais2013.pdf $>$. Acesso em 12 fev 2016.

FERNANDES, C. B.S.; CUNHA, M. S. da. Análise estrutural-diferencial do emprego formal: o setor industrial paranaense. A Economia em Revista v. 18, n. 1, p. 27-36, 2010.

FERNANDES, C. B.S.; CUNHA, M. S. da. As transformações recentes no mercado de trabalho paranaense: uma aplicação do método shift-share. Revista de Economia, v. 37, n. 1 (ano 35), p. 149-168, 2011.

IBGE - Instituto Brasileiro de Geografia e Estatística. Microrregiões. 2016a. Disponível em: <http://www.ngb.ibge.gov.br/Default.aspx?pagina=micro >. Acesso em: 6 jan 2016.

IBGE - Instituto Brasileiro de Geografia e Estatística. Brasil tem mais mulheres. 2016b. Disponível em: < http://7a12.ibge.gov.br/voce-sabia/curiosidades/brasil-tem-maismulheres.html> Acesso em: 20 jan 2016.

MARTINI, L. ; RIPPEL, R. ; FERRERA DE LIMA, J. . A Inserção Produtiva Feminina no Mercado de Trabalho na Região Sul 1996 a 2006. In: V Seminário Internacional sobre Desenvolvimento Regional, 2011, Santa Cruz do Sul RS. Anais.... Santa Cruz do Sul RS: UNISC, v. 01. p. 60-75, 2011.

MTE - Ministério do Trabalho e Emprego. Características do Emprego Formal - RAIS 2014: principais resultados. 2016. Disponível em: <http://portalfat.mte.gov.br/wpcontent/uploads/2016/03/Caracter\%C3\%ADsticas-do-Emprego-Formal-segundo-aRela\%C3\%A7\%C3\%A3o-Anual-de-Informa\%C3\%A7\%C3\%B5es-Sociais-201431082014.pdf >. Acesso em: 6 jan 2016.

MATTEI, L.; VENTURI, A. Evolução e qualificação do mercado formal de trabalho em Santa Catarina entre 1991 e 2005. Cadernos de Economia. Ano 11, n. 21, p. 95-118, 2007.

RAIS - Relação Anual de Informações Sociais. O que é RAIS? 2016. Disponível em: <http://www.rais.gov.br/sitio/sobre.jsf >. Acesso em: 3 fev 2016.

RAIS - Relação Anual de Informações Sociais; MTE - Ministério do Trabalho e Emprego. Dados e estatísticas. 2016. Disponível em: 〈http://acesso.mte.gov.br/portal-pdet/ >. Acesso em: 5 jan 2016.

SANTOS, L. dos; ARUTO, P. C. Gênero e trabalho em Santa Catarina: dados sobre trabalhadores e trabalhadoras no Estado Catarinense. Relatório da Coordenação Estadual do Sistema Nacional de Emprego - SINE. Florianópolis, 2012. 